\title{
Decidual cell expressed tissue factor promotes endometrial hemostasis while mediating abruption associated preterm birth
}

\author{
Saeed Faramarzi, Umit A. Kayisli, Ozlem Kayisli, Murat Basar, John Shapiro, \\ Nihan Semerci, Joseph Huang, Longzhu Piao, Frederick Schatz", \\ Charles J. Lockwood \\ Department of Obstetrics, Gynecology, Ohio State University School of Medicine, Biomedical Research Tower, Columbus, USA; \\ *Corresponding Author: Frederick.Schatz@osumc.edu
}

Received 20 July 2013; revised 18 September 2013; accepted 26 September 2013

Copyright (C) 2013 Saeed Faramarzi et al. This is an open access article distributed under the Creative Commons Attribution License, which permits unrestricted use, distribution, and reproduction in any medium, provided the original work is properly cited.

\section{ABSTRACT}

During human pregnancy, progesterone induced decidual cells protect against hemorrhage: 1) as endovascular trophoblast breech and remodel uterine blood vessels; and 2) in the third stage of labor following preterm and term delivery. Decidual cells promote hemostasis through enhanced expression of tissue factor (TF), the primary initiator of hemostasis via thrombin generation, and plasminogen activator inhibitor-1, which inactivates tissue type plasminogen activator, the primary fibrinolytic agent. Abruptions (decidual hemorrhage) produce excess thrombin which acts as autocrine/paracrine inducer of decidual cell expressed matrix metalloproteinases and of neutrophil chemoattractant and activator, interleukin-8. The latter mediates aseptic abruption-related neutrophil infiltration. During abruptions, decidual cell and neutrophil-derived proteases effectively degrade the decidual and fetal membrane extracellular matrix to promote preterm premature rupture of the membranes and preterm delivery (PTD). Decidual cell-derived thrombin weakens the amniotic membrane and lowers decidual cell-expressed progesterone receptor levels by increasing phospho-ERK1/2 signaling. The resulting functional progesterone withdrawal accompanies PTD.

Keywords: Preterm Birth; Abruption; Hemostasis; Tissue Factor; Thrombin

\section{EXPRESSION OF TISSUE FACTOR} (TF) BY DECIDUALIZED ENDOMETRIAL STROMAL CELLS PROMOTES HEMOSTASIS DURING THE MENSTRUAL CYCLE AND PREGNANCY

During a woman's reproductive years, ovary-derived circulating estradiol (E2) and progesterone (P4) target the functional endometrial layer to induce cyclical changes that prepare it for implantation. Non-fertile cycles lead to sloughing of the endometrium in the menstrual fluid; restoration begins in association with hypoxia induced angiogenesis in the follicular phase of the next cycle as rising circulating E2 levels initiate cell proliferation. Following ovulation, an increase in circulating P4 levels stimulates E2-primed endometrial cells in the presence of a second peak of E2 to stop their proliferation and initiate differentiation. Consequently, endometrial glands become torturous and secrete an array of products that markedly affect the uterine milieu encountered by the implanting blastocyst while the luminal epithelium is prepared for blastocyst attachment. The stromal cells undergo decidualization, which represents a complex series of morphological and biochemical changes that transform precursor stromal cells into decidual cells. The decidualization reaction is initiated around blood vessels and under the glands [1].

Under continued E2 and P4 stimulation, decidualization spreads throughout the luteal phase endometrium [2]. Integral to the decidualization process is a marked alteration in the expression of proteins that promote hemostatsis and enhance vascular stability. Chief among these is tissue factor (TF), a $47 \mathrm{kDa}$ trans-cell membrane glycol- 
protein member of the class-2 cytokine receptor family comprised of a hydrophilic extracellular domain, membrane-spanning hydrophobic domain and cytoplasmic tail. Under physiological conditions, endothelial cells do not express TF, whereas it is expressed constitutively at perivascular sites such as the adventitia of arteries and veins and in the parenchyma of various organs. Here TF forms a "hemostatic envelope" that protects against vascular injury by promoting binding of plasma-derived factor VII or its active form FVIIa to trans-cell membrane TF to trigger coagulation [3]. The clotting cascade depicted in Figure 1 indicates that TF/VIIa complex activates either FX (extrinsic pathway) or FIX (intrinsic pathway) to initiate a series of interactions among various clotting factors that culminate in proteolytic cleavage of prothrombin to thrombin, that then promotes hemostasis by forming the fibrin clot [4]. Figure 1 also indicates central roles for tissue-type plasminogen activator (tPA) and plasminogen activator inhibitor type-one (PAI-1) in modulating hemostasis. Specifically, tPA acts as the primary fibrinolytic agent, which counteracts the prothrombotic

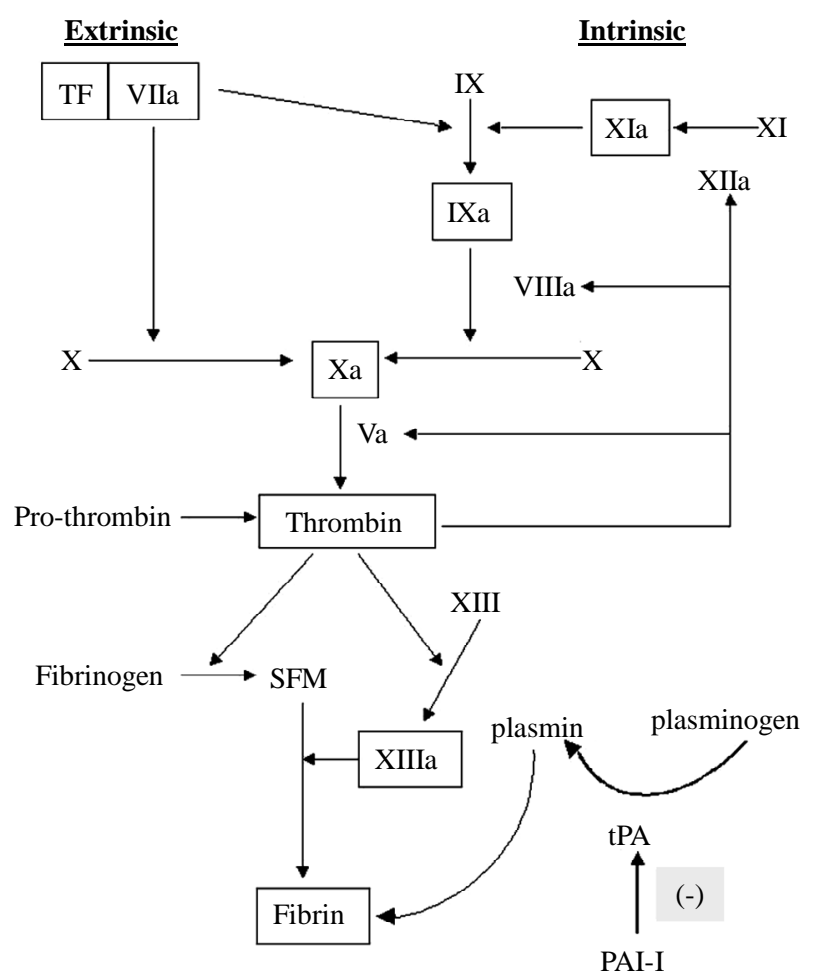

Figure 1. The clotting cascade. The TF-FVIIa complex of the extrinsic pathway initiates blood coagulation by activating FX directly or indirectly by activating FIX of the intrinsic pathway. Thrombin plays a pivotal role is this process by activating several proteases and cofactors. Specifically, thrombin cleaves fibrinogen to soluble fibrin monomers (SFM). These are crosslinked by FXIIa and thrombin activated platelets (not shown) to form the fibrin clot. Fibrin is degraded by plasmin formed by tissue type plasminogen activator (tPA). The action of tPA is regulated by its fast inactivator, PAI-1. action of TF by binding to fibrin and cleaving Arg560Val561 in its preferred substrate, plasminogen. The resulting generation of plasmin efficiently degrades fibrin. Its role as the fast inactivator of tPA enables PAI-1 to plays a critical role in determining the hemostatic balance [5].

\section{TF EXPRESSION IS CRUCIAL TO SPECIES SURVIVAL}

The relative magnitude of TF expression conforms to a tissue-specific pattern. Specifically, low TF levels are present in the liver, spleen, skeletal muscle and thymus where hemostasis appears to depend primarily on the slower acting intrinsic coagulation pathway [6] (Figure 1). By contrast, the presence of high TF levels in the placenta, skin, heart, lung, brain and uterus is consistent with a requirement for accelerated hemostatic protection utilizing the faster extrinsic coagulation pathway. That no human genetic TF deficiency has been described indicates both the critical importance of TF expression to human survival while precluding direct evaluation of its absence in humans [6]. In mice, knocking out TF gene expression results in embryonic lethality. Specifically, TF null mice develop fragile vessels and die of hemorrhage in utero. However, incorporation of a human gene that expresses TF at only $1 \%$ of wild type levels rescues the knockout mice and produces live born pups. Adult low-TF mice exhibit hemostatic defects in tissues that normally express high levels of TF such as heart, lung, uterus and placenta [6]. In the mouse uterine wall, expression of high levels of TF in epithelial cells protects against hemorrhage during gestation as well as during the post-partum period. Pregnant low TF mice experience formation of blood pools in the placental labyrinth as well as high fatality rates postpartum [6].

\section{HUMAN DECIDUAL CELL TF EXPRESSION PROMOTES GESTATIONAL HEMOSTASIS}

Stimulation by circulating E2 and P4 continues to induce the decidualization reaction throughout human pregnancy. The crucial role played by the extrinsic coagulation pathway mediated by TF-expressing decidual cells in maintaining hemostasis during human pregnancy is evident in the events after implantation and subsequent placentation. Implantation of the blastocyst is followed by cytotrophoblast invasion of the decidua. Initially, cytotrophoblast breach endometrial capillaries and venules embedded in a matrix of decidual cells expressing high levels of TF. This invasive process institutes the primordial uteroplacental circulation and provides the embryo with a vital source of oxygen and nutrients while removing carbon dioxide and other waste products [7]. How- 
ever, it also risks potential pregnancy-terminating hemorrhage as indicated by the phenomenon of "chemical pregnancy”, which is characterized by the transient appearance of trophoblast-derived HCG in maternal blood followed by local decidual bleeding $[8,9]$.

Subsequent to these early pregnancy events, extravillous interstitial cytotrophoblast traverse the decidua to breach and remodel spiral arteries and arterioles into low-resistance, high-capacity vessels $[10,11]$. The resulting increase in uteroplacental blood flow provides vital nutrients and oxygen to the developing fetal-placental unit. Depending on the gestational age of occurrence, decidual hemorrhage during this period is associated with spontaneous abortion, abruption with or without stillbirth or preterm birth [12-14]. However, decidual cell-expressed TF is temporally and spatially positioned to promote local hemostasis thereby counteracting the threat of bleeding during both the initial and subsequent periods of endovascular cytotrophoblast invasion. Among cells at the maternal-fetal interface in human term decidua, immunoreactive TF levels are highest in decidual cells [15]. By contrast, adjacent interstitial trophoblasts are essentially devoid of TF immunostaining [15]. Thus, continued elevation of TF expression by decidual cells protects against the hemostatic demands of delivery both preterm and at term.

\section{THROMBIN CELLULAR EFFECTS MEDIATED BY PROTEASE ACTIVATED RECEPTORS (PARS)}

In addition to promoting hemostasis, the generation of thrombin by TF also affects a multitude of biological functions through thrombin's binding to and activation of members of the protease activated receptor (PAR) family, which is comprised of four distinct "seven membrane" G protein coupled receptors. Thrombin promotes proliferation and chemotaxis of immune and mesenchymal cells and activates endothelial cells via PAR-1, 3 and 4, whereas PAR-2 acts as a receptor for trypsin and trypsinlike enzymes including the TF/VIIa complex. In addition, PAR-1 and PAR-2 can be activated by FXa [16]. As exemplified by thrombin, after each PAR ligand binds to its specific receptor, its serine protease domain cleaves that PAR to expose an N-terminal tethered ligand domain that autoactivates the cleaved receptor [17]. Previously, our laboratory found that stromal cells from cycling human endometrium express PAR-1 [18] and that incubation of such cultured stromal cells with thrombin or TRAP, a synthetic peptide activator of PAR-1, enhances secreted levels of the primary angiogenic agent vascular endothelial growth factor [19]. Moreover, as detailed below, cultured third trimester decidual cells continue to respond to thrombin with enhanced expression of PAR-mediated endpoints implicated in the genesis of preterm premature rupture of the membranes (PPROM) and preterm delivery (PTD).

\section{ABRUPTIONS EXPLOIT DECIDUAL HEMOSTATIC FACTORS TO ELICIT PPROM AND PTD}

\subsection{Abruption Type, Incidence and Associated Pathologies}

From implantation through delivery, successful human pregnancy requires an increase in hemostatic potential [20] that is reflected in enhanced generation of thrombin and fibrin across gestation as measured by elevated circulating levels of thrombin-antithrombin (TAT) complexes [21]. The capacity for human decidua to generate thrombin is indicated by our observations that: 1) prominent immunostaining for $\mathrm{TF}$ is localized to the cell membranes of decidual cells from first trimester as well as term decidua; and 2) medroxyprogesterone acetate (MPA) increases, and thrombin further increases, TF mRNA and protein expression in cultured human term decidual cells [15]. Abruptions involve a shift in the hemostatic/hemorrhagic equilibrium towards the latter.

In human pregnancies, bleeding into the decidua basalis can occur as a concealed abruption comprising between $10 \%$ - $35 \%$ of all abruptions, and helping to account for the common clinical underestimation of abruption-related blood loss [22,23]. However, most cases of abruption lead to overt vaginal bleeding. Such bleeding can originate from hemorrhage in either the decidua basalis (placental abruption) or decidua parietalis (retrochorionic hematoma). A 7-fold increased risk of PPROM is associated with vaginal bleeding in more than one trimester [24-26]. A particularly strong association exists between abruption and PPROM between 22 - 32 weeks. During this period, abruptions occur in $37.5 \%$ of PPROM cases versus only $0.8 \%$ of patients delivering at term $(\mathrm{p}<$ 0.01) [27].

While a strong relationship exists between intra-amniotic infection and PPROM, the frequent occurrence of vaginal bleeding indicates that placental abruption (i.e., decidual hemorrhage) is also a common antecedent of PPROM [25]. Occult decidual hemorrhage and retrochorionic hematoma formation as reflected in hemosiderin deposition has been reported in nearly $40 \%$ of patients with PPROM compared with only about $1 \%$ at term ( $\mathrm{p}<$ 0.01 ) revealing the robust association that exists between PPROM and abruption. Previously, our laboratory found that thrombin activation, as measured by elevated plasma TAT levels during the second trimester predicts subsequent occurrence of PPROM with high sensitivity and specificity [28]. Elevated circulating TAT levels during preterm labor were also found to predict PPROM and PTD [29]. Abruptions are estimated to occur in up to 
$1.8 \%$ of pregnancies and their incidence appears to be increasing [30,31]. Abruptions associated with preterm labor (PTL) and PPROM usually reflect sub-acute, chronic processes. However, acute abruptions can lead to maternal and fetal demise. Approximately, $10 \%$ of all cases of PTDs are linked to bleeding events [32]. Among African-American women, there is a disproportionately high abruption rate associated with hypertension [33]. The incidence of abruption is highest between 24 and 28 weeks of gestation and decreases as gestation advances [34].

Ischemic placental diseases normally associated with preeclampsia and idiopathic fetal growth restriction accompany 50\% of all PTDs with or without abruption [24]. The common primary defect in these cases is shallow endovascular trophoblast invasion of the decidua resulting in impaired spiral artery remodeling [24,35]. Other placental lesions associated with abruption include spiral artery thrombosis [27] and sclerotic lesions in myometrial arteries [36]. Inherited thrombophilias also appear to be linked with abruptions [37]. Women experiencing abruption also face long-term health risks [38]. Specifically, placental abruption accompanied by fetal compromise is associated with the delayed appearance of maternal cardiovascular sequelae as determined in a population-based study of more than one million women [39]. Placental abruptions are also associated with immediate maternal sequelae initiated by severe hemorrhage such as hypotension, hysterectomy, disseminated intravascular coagulation as well as multisystem organ failure. Maternal mortality is estimated to be as high as $1 \%$ [40].

\subsection{Thrombin Targets Decidual Cells to Induce Abruption-Related PPROM and PTD}

Observations made in our laboratory suggest that decidual cell-derived thrombin plays multiple roles integral to abruption-associated PPROM. Specifically, in vitro studies demonstrated that incubation of cultured term decidual cells with thrombin induces mRNA and protein expression of matrix metalloproteinases (MMP)-1 and 3 $[41,42]$ as well as that of interleukin-8 (IL-8) [43] a potent neutrophil chemoattractant and activator [44]. Moreover, decidua basalis from patients with abruption-induced PPROM, in the absence of clinical evidence of infection, contain a dense aseptic neutrophil infiltrate accompanied by elevated levels of IL-8 that co-localized with decidual fibrin deposits as determined by PicroMallory staining [43]. These observations are consistent with excess local generation of thrombin, which cleaves fibrinogen to form fibrin (Figure 1).

Neutrophils contribute to PPROM by serving as rich sources of elastase, collagenase and MMP-9 [45]. These proteases exhibit individual and common extracellular matrix (ECM) degrading activities [46-48]. In addition to promoting ECM degradation, targeting of human fetal membranes by thrombin elicits other changes consistent with abruption-related PPROM. Thus, thrombin directly weakens preparations of amniotic membrane, which serves as the major load-bearing fetal membrane component, via induction of tissue remodeling and apoptotic markers [49]. In the rat, in vitro and in vivo observations reveal that thrombin is a strong uterotonic effector whose action is independent of prostaglandin production [50]. An increase in myometrial contractions in the presence of intrauterine bleeding is consistent with the onset of PTL associated with vaginal bleeding [51].

\subsection{Thrombin Induced Functional Progesterone Withdrawal in Decidual Cells Promotes Abruption-Related PPROM and PTD}

Throughout mammalian pregnancy elevated circulating P4 levels maintain myometrial quiescence [52]. In most mammals, a decline in circulating P4 levels triggers parturition. However, in humans, some higher primates and in the guinea pig, placental P4 production and plasma P4 levels remain elevated until delivery. This phenomenon suggests that parturition is induced by "functional P4 withdrawal" likely reflecting lower levels of uterine progesterone receptors [52] and/or a shift in the PR isoform ratio in which dysfunctional, pro-inflammatory PRA becomes dominant over functional PR-B [53]. Evidence that abruptions are accompanied by functional P4 withdrawal was obtained by performing immunostaining of human placental sections with a primary antibody recognizing both PR-A and PR-B [54]. We observed that among the major resident cell types at the maternal-fetal interface, PR is localized exclusively in the nuclei of vimentin-positive decidual cells. And that decidual cell nuclei in abruption sections displayed significantly lower PR HSCOREs versus decidual cell nuclei from gestational age-matched control specimens [54]. Immunostaining also revealed that levels of signal transduction mediator, phospho-ERK1/2, are higher in the decidual cells of abruption versus control decidua, whereas total immunoreactive ERK 1/2 levels are similar between the abruption and control decidua. Complementing these in situ observations, Western blotting of nuclear extracts from primary leukocyte-free term decidual cells determined that: 1) decidual cells express both PR-A and PR-B; 2) E2 enhances levels of both isoforms; and 3) E2 plus medroxyprogesterone acetate (MPA) produces intermediate levels of both isoforms [54]. These differential steroid responses are consistent with both the priming action of E2 on endometrial PR expression as well as the sustained expression of PR within the steroid milieu of pregnancy [55]. In co-incubations with E2 or E2 + MPA, thrombin 
elicited a concentration-dependent lowering of PR-A and PR-B levels in the cultured DCs. This reduction in PR expression proved to be mediated by a mechanism involving enhanced phospho-ERK1/2 signaling. Additional observations made on cultured term decidual cells found that thrombin: 1) lowered steady state PR mRNA levels; 2) inhibits PR receptor binding to radio-labeled P4; and 3) reduced binding of PR to its cognate DNA elements in electrophoretic mobility gel shift assays [54].

\section{CONCLUSION}

Taken together, these observations indicate that excess thrombin derived from decidual cell expressed TF acts as an autocrine/paracrine effector that induces abruptionassociated PTD by inducing functional P4 withdrawal in decidual cells. These findings complement our earlier observations indicating that such decidual cell-derived thrombin also elicits PPROM and PTD by acting in autocrine/paracrine fashion to enhance expression of decidual ECM degrading proteases [41,42], by inducing expression of the neutrophil chemoattractant and activator, IL-8 [43] and by directly weakening the amnion [49].

\section{REFERENCES}

[1] Bell, S. (1990) Contraception and mechanisms of endometrial bleeding. In: D’Arcangues, C., et al., Eds., Decidualization and Relevance to Menstruation, Cambridge University Press, Cambridge, 188.

[2] Tabanelli, S., Tang, B. and Gurpide, E. (1992) In vitro decidualization of human endometrial stromal cells. The Journal of Steroid Biochemistry and Molecular Biology, 42, 337-344. http://dx.doi.org/10.1016/0960-0760(92)90137-8

[3] Mackman, N., Tilley, R.E. and Key, N.S. (2007) Role of the extrinsic pathway of blood coagulation in hemostasis and thrombosis. Arteriosclerosis, Thrombosis, and Vascular Biology, 27, 1687-1693.

http://dx.doi.org/10.1161/ATVBAHA.107.141911

[4] Tilley, R. and Mackman, N. (2006) Tissue factor in hemostasis and thrombosis. Semin Thromb Hemost, 32, 510. http://dx.doi.org/10.1055/s-2006-933335

[5] Mignatti, P. and Rifkin, D.B. (1993) Biology and biochemistry of proteinases in tumor invasion. Physiological Review, 73, 161-195.

[6] Mackman, N. (2004) Role of tissue factor in hemostasis, thrombosis, and vascular development. Arteriosclerosis, Thrombosis, and Vascular Biology, 24, 1015-1022. http://dx.doi.org/10.1161/01.ATV.0000130465.23430.74

[7] Moore (1988) The developing human: Clinically oriented embryology, 4th Edition, 40.

[8] Levy, A.P., Levy, N.S. and Goldberg, M.A. (1996) Posttranscriptional regulation of vascular endothelial growth factor by hypoxia. Journal of Biological Chemistry, 271, 2746-2753. http://dx.doi.org/10.1074/jbc.271.5.2746
[9] Oka, C., et al. (1991) Chemical abortion in patients with recurrent fetal loss. Nihon Sanka Fujinka Gakkai Zasshi, 43, 239-240.

[10] Pijnenborg, R., Vercruysse, L. and Hanssens, M. (2006) The uterine spiral arteries in human pregnancy: Facts and controversies. Placenta, 27, 939-958. http://dx.doi.org/10.1016/j.placenta.2005.12.006

[11] Brosens, I.A., Robertson, W.B. and Dixon, H.G. (1972) The role of the spiral arteries in the pathogenesis of preeclampsia. Obstetrical and Gynecological Annals, 1, 177191.

[12] Edmonds, D.K., et al. (1982) Early embryonic mortality in women. Fertility and Sterility, 38, 447-453.

[13] Miller, J.F., et al. (1980) Fetal loss after implantation: A prospective study. The Lancet, 316, 554-556. http://dx.doi.org/10.1016/S0140-6736(80)91991-1

[14] Shanklin, D.R. and Scott, J.S. (1975) Massive subchorial thrombohaematoma (Breus' mole). British Journal of Obstetrics and Gynecology, 82, 476-487. http://dx.doi.org/10.1111/j.1471-0528.1975.tb00673.x

[15] Lockwood, C.J., et al. (2009) Progestin and thrombin regulate tissue factor expression in human term decidual cells. Journal of Clinical Endocrinology \& Metabolism, 94, 2164-2170. http://dx.doi.org/10.1210/jc.2009-0065

[16] Coughlin, S.R. (2005) Protease-activated receptors in hemostasis, thrombosis and vascular biology. Journal of Thrombosis and Haemostasis, 3, 1800-1814. http://dx.doi.org/10.1111/j.1538-7836.2005.01377.x

[17] Macfarlane, S.R., et al. (2001) Proteinase-activated receptors. Pharmacological Review, 53, 245-282.

[18] Lockwood, C.J., et al. (1996) Effects of thrombin on steroid-modulated cultured endometrial stromal cell fibrinolytic potential. The Journal of Clinical Endocrinology \& Metabolism, 81, 107-112. http://dx.doi.org/10.1210/jc.81.1.107

[19] Lockwood, C.J., et al. (2002) Differential effects of thrombin and hypoxia on endometrial stromal and glandular epithelial cell vascular endothelial growth factor expression. The Journal of Clinical Endocrinology \& Metabolism, 87, 4280-4286.

http://dx.doi.org/10.1210/jc.2001-011969

[20] Clark, P. (2003) Changes of hemostasis variables during pregnancy. Seminars in Vascular Medicine, 3, 13-24. http://dx.doi.org/10.1055/s-2003-38329

[21] Bremme, K., et al. (1992) Enhanced thrombin generation and fibrinolytic activity in normal pregnancy and the puerperium. Obstetrics \& Gynecology, 80, 132-137.

[22] AR, K. and Drukker, J.E. (1986) Bleeding in late pregnancy: Antepartum bleeding. In: RH, H. and MS, C., Eds., High Risk Pregnancy: A Team Approach, Saunders, Philadelphia, 547.

[23] R, F. and W, R. (1989) Bleeding during the latter half of pregnancy. In: C, I., Ed., High Risk Pregnancy: A Team Approach, Oxford University Press, London, 89.

[24] Ananth, C.V., et al. (2007) Recurrence of ischemic placental disease. Obstetrics \& Gynecology, 110, 128-133. http://dx.doi.org/10.1097/01.AOG.0000266983.77458.71 
[25] Harger, J.H., et al. (1990) Risk factors for preterm premature rupture of fetal membranes: A multicenter case-control study. American Journal of Obstetrics and Gynecology, 163, 130-137.

http://dx.doi.org/10.1016/S0002-9378(11)90686-3

[26] Williams, M.A., et al. (1991) Adverse infant outcomes associated with first-trimester vaginal bleeding. Obstetrics \& Gynecology, 78, 14-18.

[27] Salafia, C.M., et al. (1995) Histologic evidence of old intrauterine bleeding is more frequent in prematurity. American Journal of Obstetrics and Gynecology, 173, 10651070. http://dx.doi.org/10.1016/0002-9378(95)91327-0

[28] Rosen, T., et al. (2001) Plasma levels of thrombinantithrombin complexes predict preterm premature rupture of the fetal membranes. Journal of Maternal-Fetal Medicine, 10, 297-300. http://dx.doi.org/10.1080/jmf.10.5.297.300

[29] Elovitz, M.A., et al. (2000) The mechanisms underlying the stimulatory effects of thrombin on myometrial smooth muscle. American Journal of Obstetrics and Gynecology, 183, 674-681. http://dx.doi.org/10.1067/mob.2000.106751

[30] Hall, D.R. (2009) Abruptio placentae and disseminated intravascular coagulopathy. Seminars in Perinatology, 33, 189-195. http://dx.doi.org/10.1053/j.semperi.2009.02.005

[31] Rasmussen, S., et al. (1996) The occurrence of placental abruption in Norway 1967-1991. Acta Obstetricia et Gynecologica Scandinavica, 75, 222-228. http://dx.doi.org/10.3109/00016349609047091

[32] Ananth Cv, B.G.S.S.D.A.L.R.H. (1999) PLacental abruption and adverse perinatal outcomes. JAMA: The Journal of the American Medical Association, 282, 1646-1651. http://dx.doi.org/10.1001/jama.282.17.1646

[33] Ananth, C.V., et al. (2005) Trends in twin preterm birth subtypes in the United States, 1989 through 2000: Impact on perinatal mortality. American Journal of Obstetrics and Gynecology, 193, 1076.e1-1076.e9.

[34] Oyelese, Y. and Ananth, C.V. (2006) Placental abruption. Obstetrics \& Gynecology, 108, 1005-1016. http://dx.doi.org/10.1097/01.AOG.0000239439.04364.9a

[35] Brosens, I., et al. (2011) The "Great Obstetrical Syndromes” are associated with disorders of deep placentation. American Journal of Obstetrics and Gynecology, 204, 193-201. http://dx.doi.org/10.1016/j.ajog.2010.08.009

[36] Naeye, R.L. (1983) Maternal age, obstetric complications, and the outcome of pregnancy. Obstetrics \& Gynecology, 61, 210-216.

[37] Roque, H., et al. (2004) Maternal thrombophilias are not associated with early pregnancy loss. Thrombosis and Haemostasis, 91, 290-295.

[38] Lykke, J.A., Paidas, M.J. and Langhoff-Roos, J. (2009) Recurring complications in second pregnancy. Obstetrics \& Gynecology, 113, 1217-1224.

[39] Ray, J.G., et al. (2005) Cardiovascular health after maternal placental syndromes (CHAMPS): Population-based retrospective cohort study. Lancet, 366, 1797-1803. http://dx.doi.org/10.1016/S0140-6736(05)67726-4

[40] Tikkanen, M., et al. (2009) Maternal deaths in Finland:
Focus on placental abruption. Acta Obstetricia et Gynecologica Scandinavica, 88, 1124-1127. http://dx.doi.org/10.1080/00016340903214940

[41] Rosen, T., et al. (2002) Thrombin-enhanced matrix metalloproteinase-1 expression: A mechanism linking placental abruption with premature rupture of the membranes. Journal of Maternal-Fetal and Neonatal Medicine, 11, 11-17. http://dx.doi.org/10.1080/jmf.11.1.11.17

[42] Mackenzie, A.P., et al. (2004) Mechanisms of abruption-induced premature rupture of the fetal membranes: Thrombin enhanced decidual matrix metalloproteinase-3 (stromelysin-1) expression. American Journal of Obstetrics and Gynecology, 191, 1996-2001. http://dx.doi.org/10.1016/j.ajog.2004.08.003

[43] Lockwood, C.J., et al. (2005) Mechanisms of abruption-induced premature rupture of the fetal membranes: Thrombin-enhanced interleukin-8 expression in term decidua. The American Journal of Pathology, 167, 14431449. http://dx.doi.org/10.1016/S0002-9440(10)61230-8

[44] Baggiolini, M., Walz, A. and Kunkel, S.L. (1989) Neutrophil-activating peptide-1/interleukin 8 , a novel cytokine that activates neutrophils. The Journal of Clinical Investigation, 84, 1045-1049. http://dx.doi.org/10.1172/JCI114265

[45] Van den Steen, P.E., et al. (2000) Neutrophil gelatinase B potentiates interleukin-8 tenfold by aminoterminal processing, whereas it degrades CTAP-III, PF-4, and GROalpha and leaves RANTES and MCP-2 intact. Blood, 96, 2673-2681.

[46] Westermarck, J. and Kahari, V.M. (1999) Regulation of matrix metalloproteinase expression in tumor invasion. The FASEB Journal, 13, 781-792.

[47] Cohen, M., Meisser, A. and Bischof, P. (2006) Metalloproteinases and human placental invasiveness. Placenta, 27, 783-793. http://dx.doi.org/10.1016/j.placenta.2005.08.006

[48] Nagase, H., Visse, R. and Murphy, G. (2006) Structure and function of matrix metalloproteinases and TIMPs. Cardiovascular Research, 69, 562-573. http://dx.doi.org/10.1016/j.cardiores.2005.12.002

[49] Kumar, D., et al. (2011) The effects of thrombin and cytokines upon the biomechanics and remodeling of isolated amnion membrane, in vitro. Placenta, 32, 206-213. http://dx.doi.org/10.1016/j.placenta.2011.01.006

[50] Phillippe, M., Elovitz, M. and Saunders, T. (2001) Thrombin-stimulated uterine contractions in the pregnant and nonpregnant rat. Journal of the Society for Gynecologic Investigation, 8, 260-265. http://dx.doi.org/10.1016/S1071-5576(01)00121-6

[51] Elovitz, M.A., et al. (2000) Effects of thrombin on myometrial contractions in vitro and in vivo. American Journal of Obstetrics \& Gynecology, 183, 799-804. http://dx.doi.org/10.1067/mob.2000.108897

[52] Thijssen, J.H. (2005) Progesterone receptors in the human uterus and their possible role in parturition. The Journal of Steroid Biochemistry and Molecular Biology, 97, 397-400. http://dx.doi.org/10.1016/j.jsbmb.2005.08.011

[53] Mesiano, S., et al. (2002) Progesterone withdrawal and 
estrogen activation in human parturition are coordinated by progesterone receptor A expression in the myometrium. The Journal of Clinical Endocrinology \& Metabolism, 87, 2924-2930.

http://dx.doi.org/10.1210/jc.87.6.2924

[54] Lockwood, C.J., et al. (2012) Abruption-induced preterm delivery is associated with thrombin-mediated functional progesterone withdrawal in decidual cells. The American Journal of Pathology, 181, 2138-2148. http://dx.doi.org/10.1016/j.ajpath.2012.08.036

[55] Eckert, R.L. and Katzenellenbogen, B.S. (1981) Human endometrial cells in primary tissue culture: Modulation of the progesterone receptor level by natural and synthetic estrogens in vitro. The Journal of Clinical Endocrinology \& Metabolism, 52, 699-708.

http://dx.doi.org/10.1210/jcem-52-4-699 